\title{
STUDY OF ROUND CENTRAL HOLE IN BUCKLING ANALYSIS OF CROSS PLY LAMINATES
}

\author{
Amruta Pradipkumar Sonawane ${ }^{1}$ \\ ${ }^{I}$ M.E.Student, Mechanical Department, Flora Institute of Technology, Pune
}

\begin{abstract}
Laminated structures find many applications in various engineering fields namely aerospace, bio-medical, civil, marine and mechanical engineering due to easy handling, good mechanical properties and low fabrication cost. Laminated plates with round holes and other openings are extensively used as structural members in aircraft design. These holes are act sometimes as access holes, holes for hardware to pass through, or in the case of fuselage, windows and doors or simply used to reduce the weight of the structure. These laminated structures are often subjected to load in one or more direction in cycles or as intermittent load. Thus there is need to study the failure of these components under bi-axial loading with the view to optimize the shape and lay of the components so as they give maximum service and more life. In this paper bi-axial testing machine is developed to determine bucking load of different materials. Experiments are carried out on cross ply composite under various buckling loads on the biaxial testing machine. The theoretical results, analytical and experimental results are compared with each other. It is observed that the strength of Bakelite composite plates is higher than glass epoxy laminated composite plate. So Bakelite is more suitable than glass epoxy.
\end{abstract}

Keywords- Buckling, Bakelite, Ansys, Biaxial Loads

\section{INTRODUCTION}

The laminated composite materials are created to improve combination of mechanical characteristics like high strength/stiffness for lower weight, ease of handling and low fabrication cost, stability and improvement of structure aesthetics are achieved.

Different types of holes are cut into the composite laminated plates either to form ports for mechanical or electrical systems, to reduce the overall weight of composite materials, to assemble components inside the structure, to serve as doors and windows. In laminated structures, these cutouts causes failure due to increased stress concentration, high interlaminar stresses and delamination due to free edges and also due to the various in plane loading conditions. One way to reduce this failure is by testing the component for the different loading conditions before it is put into the operation.

Failure in the structures is of various types viz; creep, fatigue, alternate \& excessive stresses, bending, buckling. Among which buckling is more severe and catastrophic failure that occurs in composite structures. It depends upon the stiffness of the material not on its strength. If the structures are heavily loaded with axial compressive force then it causes failure due to buckling. The minimum compressive load which exceeds the ultimate load value is called the critical buckling load. Buckling results in elastic instability and can even collapse.

So for the reliability and safety of the design under given operating conditions it is necessary to investigate buckling behavior of structures with different characteristics. Also the maximum value of the load which the structure withstands is necessary.
There are numerous ways of reducing or preventing buckling, for example by changing the aspect ratio in plates, increasing the bucking load by changing the fibre orientation or by varying the applied load.

Scientists \& engineers have used experimental methods to determine critical bucking load which are less cumbersome and time saving as compared to numerical methods which consumes more time and require equation solving. They used INSTRON tensile testing machine for experimentation which is heavy and inflexible \& applies only uniaxial loads. In this work a biaxial tensile testing machine is designed and developed which can apply load closer to actual working condition.

\section{LITERATURE REVIEW}

Ni et. al. [1] and Mania [2], implemented a higher order shear deformation plate theory and Galerkin orthogonalisation method alongwith coordinate system transformation for buckling analysis of composite laminated plate subjected to uniaxial and biaxial compression. It is clear from study \& analysis that buckling load is different for different lamination angle. The buckling load is directly proportional to skew angle $\alpha$ for trapezoidal laminates. Aydogdu [3] and Ashok et. al. [19], has carried out the thermal buckling analysis of cross ply laminated composite beams under various boundary conditions \& uniform temperature distribution. For this three-degree-of-freedom shear deformable beam theory is used. It is concluded that some cross ply beams generally buckle when cooled and few of them does not have any effect of varying temperature. It also reported that addition of SMA fibres into laminates improves the Critical buckling temperature \& SMA can be used in high temperatures. Kumar [4], studied 
the buckling behavior of laminated composite plate using theory of plates bending with base of the classical laminate plate theory. 3-D Tsai-Hill and interlaminar failure criterion are used to determine lamina failure and failure due to onset of delamination. The effect of this buckling load decreases with reduction in thickness. The investigation of the influence of boundary conditions under flexural loading on buckling and postbuckling behavior with various sizes and shape of cutouts on the axially compressed quasi-isotropic laminate by using finite element method \& following First order shear deformation theory and von Karman's assumptions is done \& shows that failure loads for the plate with hole is less than that without holes by Kumar et. al. [5] Al-Qablan et. al. [6], studied the buckling phenomenon in simply supported orthotropic materials and laminated composite blade-stiffened panels with circular cutouts under different types of inplane loads. This work reported that the buckling load in the laminated composite panel having cutouts and stiffeners increases upto 5 times for uniaxial loading, 7 times for biaxial loading and 2 times for shear loading as compared to the perfect plate. Stability analysis is done by Rayleigh-Ritz method and buckling load factor is evaluated. Bano et. al. [7], studied the buckling response of laminates with cutout subjected to varying in-plane loads, combined with shear using higher order shear deformation theory. The plates without holes have lower buckling load value as compared to plate carrying hole. Allahbakhsh et. al. [8], represents study of laminated composite cylindrical panel with an elliptical cutout subjected to axial loading by implementing the Abaqus software. It showed that as ply angle increases load capacity increases proportionally. If the width of cutout is kept constant or varied and also height, bucking load changes correspondingly. The $\mathrm{a} / \mathrm{b}$ ratio is directly proportional to buckling load. Shariati et. al. [9] and Lakshminarayana et al. [10], presented the buckling phenomenon of perforated rectangular steel plates subjected to uniaxial compressive loading in elasto-plastic range with change in the loading bands using finite element ABAQUS \& ANSYS software. The plate is made by reinforcing graphite fibers with epoxy matrix. The plate is modeled with elliptical and round holes and subjected to CC and CS type boundary conditions. The buckling load increases with increase in the loading band. The plate with clamped support has buckling load factor twice than that of simply support. The buckling load for the plate under L4 loading condition is higher than plate with L1, L2 andL3 type loads. The buckling behavior of rectangular laminated composite plates using finite element analysis ANSYS software is reported by Singh Gaira $\mathbf{N}$. et. al. [11], The study shows that by inserting cutout buckling load decreases. Sayyad et. al. [12], evaluated the critical buckling load of thick isotropic plates carrying uniaxial and biaxial in-plane forces using an exponential shear deformation theory. The principle of virtual work is used to obtain governing buckling equations and boundary conditions. It is done for different side to thickness ratios $(\mathrm{a} / \mathrm{h})$, aspect ratios $(\mathrm{a} / \mathrm{b})$, modulus ratio (E1/E2), different boundary conditions, and varying fiber orientations for various materials. Dr. Jameel et. al [13], studied the buckling response of damaged crossply and angle ply composite laminated plates under uniform or non-uniform compressive load by using Levy method of classical laminate plate theory. The buckling load changes as the shape of cutout changed. The value of buckling load is less when size of cutout increases. Joshi et. al. [14] and Rajesh et. al. [16], performed buckling analysis of carbon/epoxy \& thin FRP cross ply rectangular laminated plate with circular \& square cut-outs under biaxial compression by using 2D modeling finite element analysis. It is seen that as aspect ratio and $\mathrm{b} / \mathrm{t}$ ratio increases buckling load for unit length decreases. The plate having hole at top has more strength as compared with bottom and center hole. It is observed that the buckling load increases with increase in number of layers for 1st five modes of different layers. Shakya et. al. [17] and Hussain et. al. [18], studied analysis of composite laminated plate using FEM and the effect of the circular cutouts on the vibration response of a symmetric angle-ply laminated plate with changing lamination angles for the range of angles $0^{\circ}$ to $90^{\circ}$ in steps of $15^{\circ}$. The attempt is made to find the effect of various cut-outs on buckling load for different stacking sequence. From result they conclude that $\left[(0 / 90)_{2}\right]_{\mathrm{s}}$ cross-ply laminate gave highest buckling load compared to other stacking sequences and fundamental natural vibration frequency is directly proportional to the stiffness of the plate and it decreases as L/h ratio increases. Dr. Reddy et. al. [20], have worked on the buckling behavior of carbon/epoxy symmetrically laminated rectangular plate. The plate is under uniaxial compressive loads and square /rectangular cutouts are made in plate then its size, orientations are changed to study its effect. The buckling load changes as the shape of cutout changed. The value of buckling load is less when size of cutout increases. Prasad et. al. [21], presented the buckling analysis of rectangular plate having various location cutouts and subjected to partial edge compression loading. So the outcome shows that stress in plate without cutout is less as compared to with cutout and this difference in stress is very minute. Swamy et. al. [22], explained the buckling response of homogeneous and heterogeneous plate with and without crack. It estimates that buckling load is more for homogeneous plate than the heterogeneous one while presence of crack and increase in aspect ratio lowers the critical buckling load. Rajappan et. al. [23], carried out the numerical analysis to determine critical buckling load for the thin rectangular plates having clamped-free-clampedfree boundary condition. The analyzed result shows the improvement of strength due to special notches and plate with rectangular notch is weaker than the plate with other notches.

\section{PROBLEM STATEMENT}

In real world applications components are subjected to multi-axial loading and from the literature review it is seen that there are machines which can perform uni-axial testing only. In this work, a biaxial buckling load test rig is developed which is used to obtain results close to actual working condition. Thus by using this machine buckling strength of any type of material can be determined. This machine can be used for the biaxial tensile and compressive testing. 


\section{OBJECTIVES}

Here biaxial tensile testing machine is developed with $1000 \mathrm{~N}$ capacity. In this work two different types of composite laminated plates namely glass epoxy and Bakelite are considered for testing. The modeling of the plate is done using Unigraphics software and is imported in ANSYS 14.5 for analysis by subjecting it to the uniform biaxial compressive load. After analysis comparison is made between two composite laminations using stresses, deformation and failure loads.

\section{EXPERIMENTAL STUDY}

\subsection{Need of Buckling Load Test Rig}

Many numerical and experimental methods are generally used for determining critical buckling load of cross ply laminated plates. Numerical methods requires equation solving which is time consuming and experimental methods used INSTRON tensile testing machine. This machine can apply only uniaxial loads and it is known that composite plates are subjected to different types of load during their service. So failure under these loads is necessary to find out. And as bucking load is more under biaxial loading condition so in order to reduce effect of buckling biaxial loads are considered here. For this buckling load test rig is developed which is of low cost and having less weight so it can be moved anywhere. The setup can also be used for performing axial tension test under biaxial loading condition.

\subsection{Manufacturing of Biaxial Tensile Testing}

\section{Machine}

The machine is developed by using different manufacturing methods. The casing plate is fabricated from structural grade steel using $\mathrm{C}$ frame which houses ball bearing that support the central bevel crown and the four bevel pinion. $80 \mathrm{~W}$ geared motor is selected in order to provide required torque to the machine. All the $\mathrm{C}$ frame casing plate and other components are welded to each other. The setup applies loads by using loader screw with specimen holder thus providing flexibility in operation.

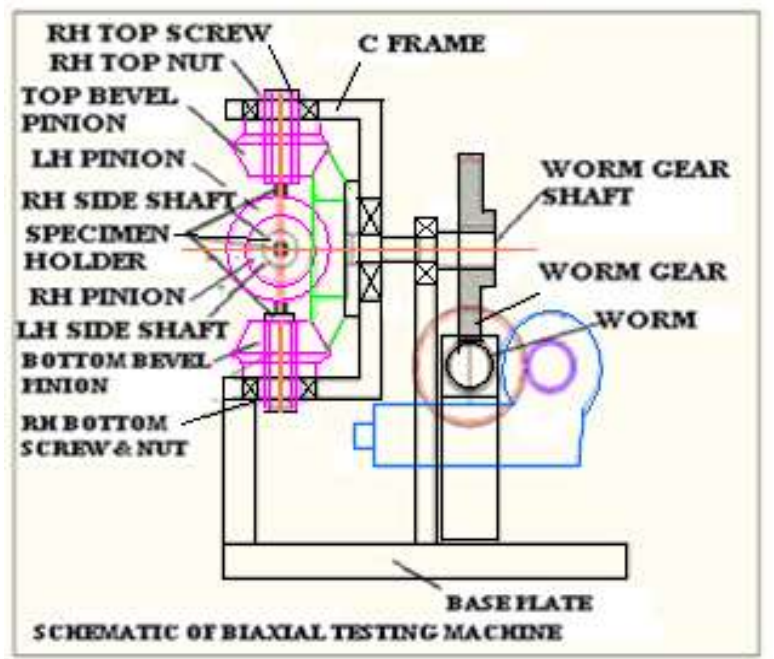

Fig. 1 Biaxial tensile testing machine

\section{EXPERIMENTAL ANALYSIS}

Experimental analysis is carried out on two cross ply laminated plates to find critical buckling load, stress \& deformation. Following two material plates are used:

1) Bakelite plate $(75 \mathrm{~mm} \times 75 \mathrm{~mm} \times 1 \mathrm{~mm})$

2) Glass epoxy $(75 \mathrm{~mm} \times 75 \mathrm{~mm} \times 1 \mathrm{~mm})$

The plates have round hole at its center with diameter 12 $\mathrm{mm}$ and number of layers is three and thickness of each layer is $0.3 \mathrm{~mm}$.

\section{Testing Method}

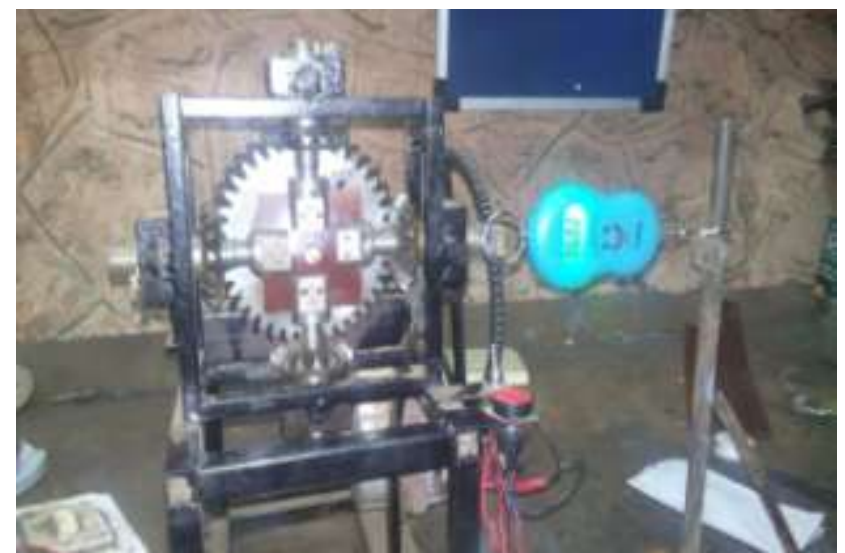

Fig. 2 Experimental Setup of Biaxial tensile testing machine

The square cross ply laminated plate is simply clamped in the specimen holder of the biaxial tensile testing machine which acts as a clamped support. The load cell is attached to one of the loader screw. To find experimental stress, failure load and deformation biaxial compressive load is applied at four edges of the plate. The load application is slow and gradual. The load is applied until the failure occurs in the laminated cross ply plate. The applied load is measured with the help of load cell and the deformation with Vernier caliper. Tests are carried on bakellite square plate ,glass epoxy plates.

The testing of a cross ply laminated plate is carried on biaxial tensile testing machine. The specimen is simply clamped at the four edges. To create simply clamped support condition for plate, specimen holders are used. These specimen holders are mounted at end of each screw. As the bevel pinion rotates, the nut fitted with screw also rotates and this rotation is converted to translation motion of screw. To check buckling behavior of the test plates, they are loaded in the biaxial compression. The deformations and failure loads are observed for plates of two different materials.

\section{STATIC STRUCTURAL ANALYSIS}

Static structural analysis is performed for validation of experimental results. The structural analysis is done in order to find out equivalent von misses stresses and deformations. If the stresses \& deformations values obtained from analysis exceeds the allowable values it will result in the failure of the structure. To avoid such a failure, this analysis is necessary. The analysis is carried out for both Bakelite \& 
Glass epoxy cross ply laminated plates using ANSYS 14.5 analysis software to determine stress \& deformation for studying the effect of round holes in buckling analysis of cross ply laminates.

The plates are modeled by using tetrahedral element having 1935 nodes and 250 elements as shown in fig. 3 . The data required for the further processing is obtained from physical testing of the plates.

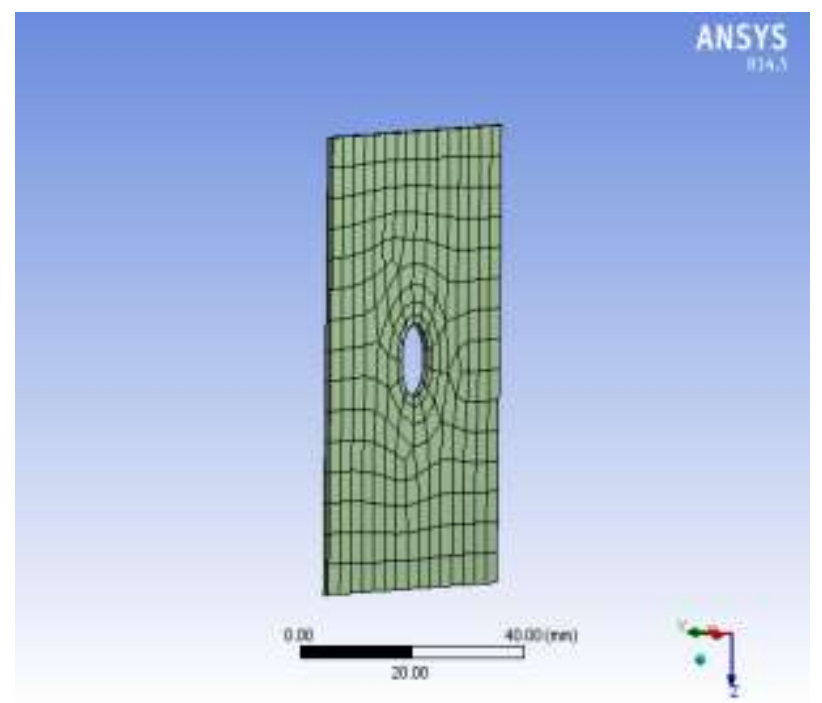

Fig. 3 Meshed model for Bakelite \& Glass epoxy

\section{RESULT AND DISCUSSION}

The analysis is done by three methods namely theoretical, analytical and experimental. The results obtained analytically and theoretically are compared with experimental results for validation.

\subsection{Theoretical Results}

1.Theoretical calculation of deformation of bakelite laminate under action of bi-axial load of $30 \mathrm{~kg}$.

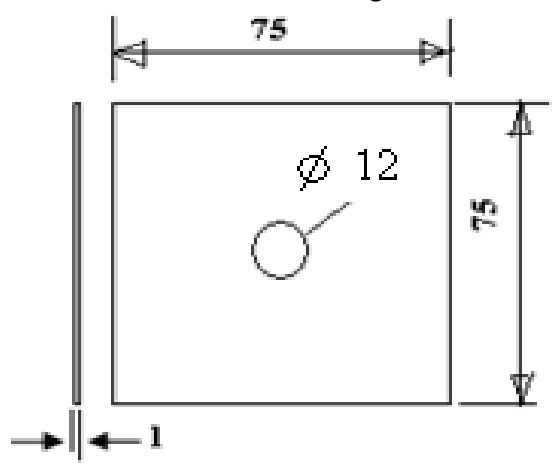

Fig.4. Plate geometry \& dimensions

Size of the plate: $75 \mathrm{~mm} \times 75 \mathrm{~mm}$

Hence, $a=b=75 \mathrm{~mm}$

$\alpha=\frac{a}{b}=\frac{75}{75}=1$

So maximum deflection of the plate

$$
\delta=C\left(1-v^{2}\right) \frac{\mathrm{w} b^{4}}{E t^{2}}
$$

where,

$\mathrm{C}=0.016$

$$
\mathrm{C}=\frac{0.032}{1+\alpha^{2}}
$$

$\vartheta=$ Poisons ratio $=0.4175$

and $\mathrm{E}=7500 \mathrm{MPa}$

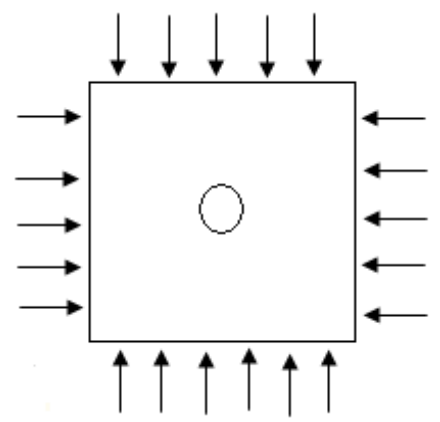

Fig.5 Load applied on plate

$\mathrm{b}=$ width $=\frac{75}{4}=18.75 \mathrm{~mm}$

$\mathrm{w}=\frac{300}{\text { area }}=0.0533 \mathrm{~N} / \mathrm{mm}^{2}$

$\mathrm{T}=$ thickness $=1 \mathrm{~mm}$

Thus

$$
\begin{aligned}
& \delta=C\left(1-\vartheta^{2}\right) \frac{\mathrm{wb}^{4}}{\mathrm{Et}^{2}} \\
& \delta=0.016\left(1-0.4175^{2}\right) \frac{0.0533 \times 18.75^{4}}{7500 \times 1^{4}} \mathrm{~mm} \\
& \delta=0.00113 \mathrm{~mm}
\end{aligned}
$$

Thus maximum theoretical deflection for Bakelite $=0.00133$ $\mathrm{mm}$

Now stress is calculated by using the formula

$\epsilon=\frac{\delta}{l}=\frac{0.00113}{18.75}=6.0266 \times 10^{-5}$

$\epsilon=\frac{\sigma}{\mathrm{E}}$

$6.0266 \times 10^{-5}=\frac{\sigma}{7500}$

$\sigma=4.52 \mathrm{~N} / \mathrm{mm}^{2}$

2.Theoretical calculation of deformation of glass epoxy laminate under action of bi-axial load of $30 \mathrm{~kg}$.

Size of the plate: $75 \mathrm{~mm} \times 75 \mathrm{~mm}$

Hence, $a=b=75 \mathrm{~mm}$

$$
\alpha=\frac{a}{b}=\frac{75}{75}=1
$$


Now maximum deflection of the plate

From equation (i)

$\delta=0.016\left(1-0.3175^{2}\right) \frac{0.03 \times 18.75^{4}}{6000 \times 1^{4}}$

$\delta=0.00973 \mathrm{~mm}$

Where

$$
\mathrm{C}=\frac{0.032}{1+\alpha^{2}}
$$

$\mathrm{C}=0.016$

$$
\begin{gathered}
v=\text { Poisons ratio }=0.3175 \\
\mathrm{~b}=\text { width }=\frac{75}{4}=18.75 \mathrm{~mm} \\
\mathrm{w}=\frac{300}{\text { area }}=0.03 \mathrm{~N} / \mathrm{mm}^{2} \\
\mathrm{E}=8500 \mathrm{MPa} \\
\mathrm{T}=\text { thickness }=1 \mathrm{~mm}
\end{gathered}
$$

Thus maximum theoretical deflection for glass epoxy = $0.00973 \mathrm{~mm}$.

Now stress is calculated by using the formula

$$
\begin{aligned}
& \epsilon=\frac{\delta}{l}=\frac{0.00973}{18.75}=5.189 \times 10^{-4} \\
& \epsilon=\left(\frac{\sigma}{E}\right) \\
& 5.189 \times 10^{-4}=\frac{\sigma}{8500} \\
& \sigma=4.41 \mathrm{~N} / \mathrm{mm}^{2}
\end{aligned}
$$

\subsection{Analytical Results}

\subsubsection{Stress and Deformation Results for Bakelite}

\section{Plate}

From static analysis of Bakelite plate maximum stress \& deformations values are obtained and are well below the permissible limit. The maximum stress value for plate is $5.0473 \mathrm{~N} / \mathrm{mm}^{2}$ which occurred in the vicinity of round hole $\&$ is well below the permissible limit $48 \mathrm{~N} / \mathrm{mm}^{2}$. The total deformation for Bakelite plate occurs at the four corners and it is about $0.7245 \mu \mathrm{m}$.

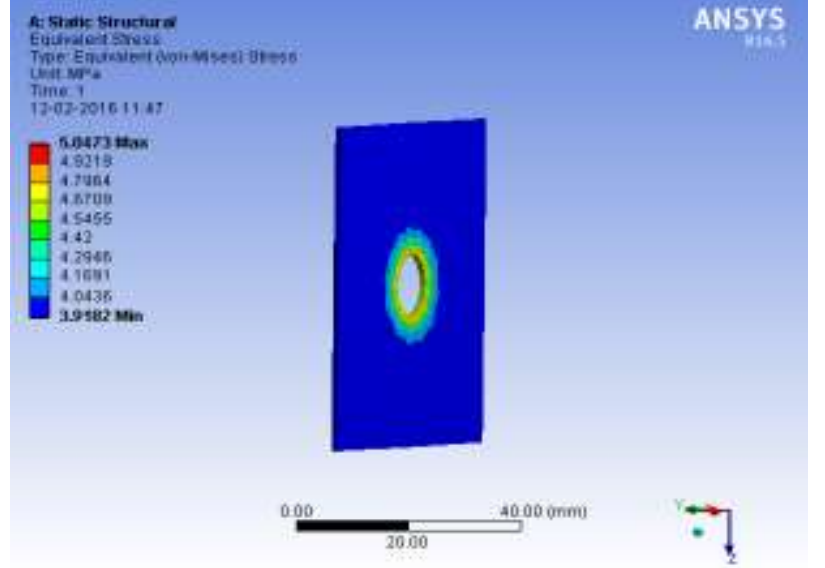

Fig. 6 Equivalent Stress for bakellite plate

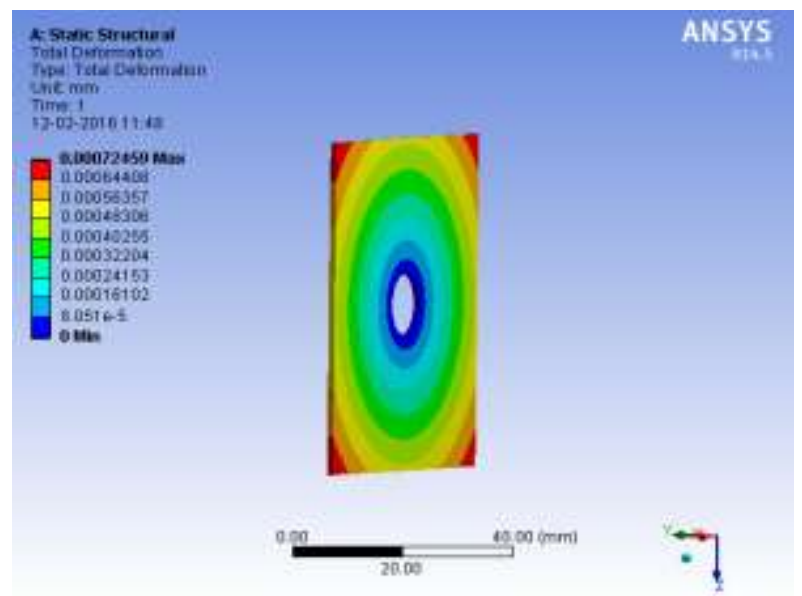

Fig. 7 Total Deformation for Bakelite plate

\subsubsection{Stress and Deformation Results for Glass Epoxy Plate}

From static analysis of glass epoxy plate the maximum Stress value for plate is $6.4012 \mathrm{~N} / \mathrm{mm}^{2}$ which occurred across the edge of round hole and is well below the permissible limit $40 \mathrm{~N} / \mathrm{mm}^{2}$. The total deformation for Glass Epoxy plate occurs at the four corners and it is about 0.9178 $\mu \mathrm{m}$, which is as shown in the figure 9 .

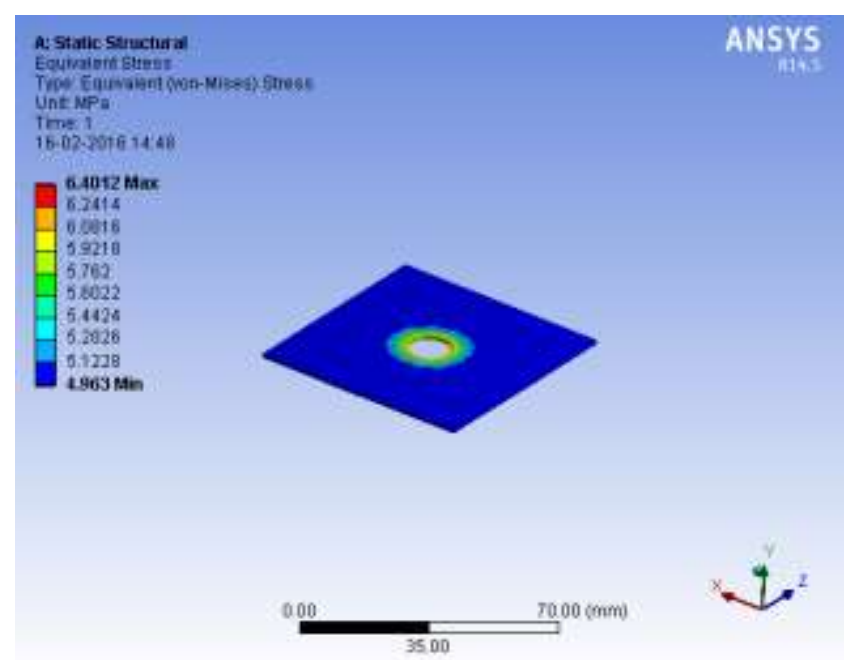

Fig. 8 Equivalent Stress for glass epoxy plate 


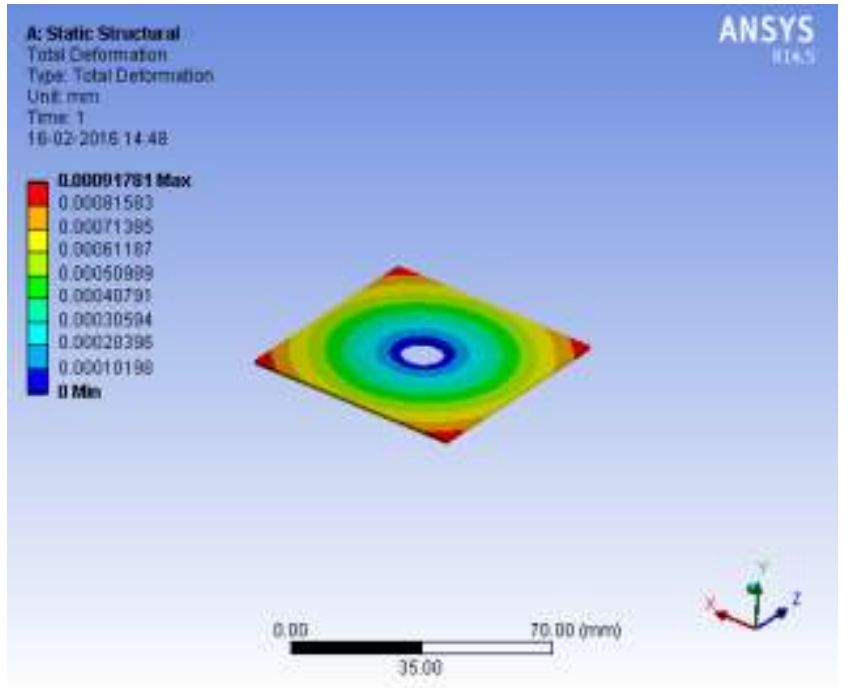

Fig. 9 Total Deformation for glass epoxy plate

\subsection{Experimental Results}

The buckling analysis is performed on the cross ply laminated square plates made of Bakelite and glass epoxy by subjecting to biaxial compressive loading. The result shows that the Bakelite plate buckles at load of $30 \mathrm{~kg}$ while the plate made of Glass epoxy has critical buckling load of 17 $\mathrm{kg}$. The corresponding deformations are measured by using Vernier caliper and are 0.001 for bakellite and 0.009 for glass epoxy.

\subsection{Comparison of Results}

The deformation due to biaxial compression for two composite laminated cross ply plates is determined. The theoretical, experimental and finite element analysis results are compared. These shows good agreement with each other. The deformation obtained for Bakelite and glass epoxy plate is shown in the table1. The stresses are also calculated for the two different plates by analytically and experimentally and are compared as shown in table 2 .

Table 1 Comparison Of Deformation Results

\begin{tabular}{|l|l|l|l|}
\hline $\begin{array}{l}\text { Plate } \\
\text { Material }\end{array}$ & $\begin{array}{l}\text { Theoretical } \\
\text { deformation } \\
\text { (mm) }\end{array}$ & $\begin{array}{l}\text { ANSYS } \\
\text { deformati } \\
\text { on }(\mathbf{m m})\end{array}$ & $\begin{array}{l}\text { Experiment } \\
\text { al } \\
\text { deformation } \\
(\mathbf{m m})\end{array}$ \\
\hline Bakellite & 0.00133 & 0.0007 & 0.001 \\
\hline $\begin{array}{l}\text { Glass } \\
\text { Epoxy }\end{array}$ & 0.00973 & 0.0009 & 0.009 \\
\hline
\end{tabular}

Table 2: comparison Of Stress Results

\begin{tabular}{|l|l|l|l|}
\hline $\begin{array}{l}\text { Plate } \\
\text { Materia } \\
\mathbf{l}\end{array}$ & $\begin{array}{l}\text { Theoretical } \\
\text { stress } \\
\left(\mathbf{N} / \mathbf{m m}^{\mathbf{2}}\right)\end{array}$ & $\begin{array}{l}\text { ANSYS } \\
\text { Von-misses } \\
\text { stress } \\
\left(\mathbf{N} / \mathbf{m m}^{\mathbf{2}}\right)\end{array}$ & $\begin{array}{l}\text { Experimenta } \\
\text { l stress } \\
\left(\mathbf{N} / \mathbf{m m}^{2}\right)\end{array}$ \\
\hline Bakellite & 4.52 & 5.0473 & 5.0222 \\
\hline $\begin{array}{l}\text { Glass } \\
\text { Epoxy }\end{array}$ & 4.41 & 6.4012 & 5.8223 \\
\hline
\end{tabular}

As the results of the theoretical, analytical and experimental deformations are close and below $0.1 \mathrm{~mm}$ permissible limit the result is valid.

The equivalent von misses stresses calculated by ANSYS and by experimental for glass epoxy are higher than that for bakellite.

\section{CONCLUSION}

The composite laminated plates with round holes at center of plates are tested experimentally for determining failure loads \& static structural analysis is done to find the total deformations, equivalent (von misses) stresses. The equivalent von misses stresses and deformations calculated for the Bakelite and glass epoxy plates are compared with each other. Also the results obtained with theoretical, analytical methods are compared with experimental method for validation purpose. The results show good agreement with each other.

1. It is observed that deformation in glass epoxy material is higher as compared to Bakelite material.

2. It is seen that buckling stress for the Bakelite laminated composite plate is lower than the buckling stress for the glass epoxy plate for the same area of the plate.

3. It is noted that buckling load for the glass epoxy square plate is lower than Bakelite square plate. The glass epoxy plate fails easily as compared to Bakelite when subjected to same biaxial compressive load. So strength of the Bakelite is greater than that of glass epoxy.

\section{REFERENCES}

[1] Ni. Qing Qing, X. Jia, M.Zenichiro, "Bucking analysis of laminated composite plate using higher order shear deformation theory".

[2] R. Mania, "Buckling analysis of trapezoidal composite sandwich plate subjected to in-plane compression", Composite Structures; 69:482-490, (2005)

[3] M. Aydogdu, "Thermal buckling analysis of cross-ply laminated composite beams with general boundary conditions", Composites Science and Technology; 67:1096-1104, (2007).

[4] Kumar, "Buckling Analysis of Woven Glass epoxy Laminated Composite Plate"M Tech Thesis NIT Rourkela, (2009)

[5] D. Kumar \& S.B. Singh," Effects of boundary conditions on buckling and post buckling responses of composite laminate with various shaped cutouts", Composite Structures 92:769-779,(2010)

[6] H. Al-Qablan., H. Dwairi, N.Shatarat, T. Rosan and T.Al-Qablan, "Stability Analysis of Composite Panels with Stiffeners and Circular Cutouts", Jordan Journal of Civil Engineering, 4(2), 2010

[7] Bano, P. M. Mohite, A. Kumar, "Buckling of Laminated Plates with Cutout using Higher Order Theory", ICCMS, 2012

[8] H. Allahbakhsh, A. Dadrasi, "Buckling Analysis of Laminated Composite Panel with Elliptical Cutout 
Subject to Axial Compression" Modeling and Simulation in Engineering, 2012

[9] M. Shariati, and A. Dadrasi, "Numerical and Experimental Investigation of Loading Band on Buckling of Perforated Rectangular Steel Plates", Research Journal of Recent Sciences, Vol. 1(10), 6371, (2012)

[10] Lakshminarayana, R. Vijaya Kumar, G. Krishna Mohana Rao, "Buckling analysis of quasi-isotropic symmetrically laminated rectangular composite plates with an elliptical/circular cutout subjected to linearly varying in-plane loading using fem", Int. Journal of Mechanics,1(16), (2012)

[11] N. Gaira, "Linear buckling analysis of laminated composite plate", International journal of engineering science \& Advanced Technology; 2(4): 886 - 891, (2012)

[12] S. Sayyad, Y.M. Ghugal, "Buckling analysis of thick isotropic plates by using exponential shear deformation theory", Applied and Computational Mechanics, 6 (2012) 185-196

[13] Prof. Dr. A.N. Jameel, "Buckling Analysis of Damaged Composite Plates under Uniform or NonUniform Compressive Load" Journal of Engineering University of Baghdad Vol. 18 N. 8, (2012)

[14] A.Joshi, P. R.Reddy, V.N. Krishnareddy, Ch. V. Sushma, "Buckling analysis of thin carbon/epoxy plate with circular cut-outs under biaxial compression by using FEA", Int. Journal of Research in Engineering and Technology, 2(10), (2013)

[15] K.M. Reddy, B. S. Reddy, R. M. Kumar, "Buckling Analysis of Laminated Composite Plates Using Finite Element Method", Int. Journal of Engineering Sciences \& Research Technology, 2(11); (2013)

[16] K. Rajesh, V. R. Rao and S. M. Babu, "Linear Buckling Analysis on Thin FRP Cross Ply Rectangular Laminates with square cut-outs of curved corners under Biaxial Compression", Int. Journal of Engineering Research \& Technology,2(12), (2013)

[17] R. Shakya, T. Sharma, R. Bahadur, "Effect of various cut-out on buckling analysis of laminated composite plate using FE simulation", ELK Asia Pacific Journals

[18] S. A.Hussain, V. Pandurangadu , K. Palani Kumar, "Vibration Analysis of Laminated Composite Plates with Holes", Int. Journal of Engineering Sciences \& ResearchTechnology,3(7) (2014)

[19] Dr. K. Ashok, "Thermal Buckling Analysis of Laminated Composite Plate", Int. Journal of Engineering Research \& Technology, 3(10), (2014)

[20] Dr. P. R. Reddy, P. S. Reddy, P.S. Reddy, "Buckling Analysis of Orthotropic Laminated Composite Plate With Rectangular Cut-Outs By Using FEA", Int. Journal of Emerging Technologies in Computational and Applied Sciences, 10(1), (2014)

[21] N.R. Prasad, J. Singh, "Buckling Analysis of Rectangular Plates with Cutouts and Partial Edge Compression", Int. Advanced Research Journal in Science, Engineering and Technology, 2(5), (2015)

[22] M. S. Swamy, A Ranjith, D. S. Sandya, S. S Badami, "Buckling Analysis of Plate Element Subjected to In
Plane Loading Using ANSYS", Int. Journal of Innovative Research in Science, Engineering and Technology, 4(5), (2015)

[23] Rajappan, Magesh, Gurunathan, "Buckling analysis in uni directional glass epoxy laminated plate", Int. Conference on Recent Advancement in Mechanical Engineering \&Technology, 137-139, (2015) 